\title{
Sistem Pendukung Keputusan Pemilihan Karyawan Berprestasi di Universitas Muhammadiyah Jember Dengan Metode Profile Matching
}

\author{
Miftah Chatibul Umam ${ }^{1}$, Deni Arifianto ${ }^{2}$, Triawan Adi Cahyanto ${ }^{3}$ \\ 1,2,3 Jurusan Teknik Informatika, Fakultas Teknik, Universitas Muhammadiyah Jember \\ Email : ${ }^{1)}$ miftahumam@hotmail.com, ${ }^{2}$ deniarifianto@unmuhjember.ac.id, ${ }^{3)}$ triawanac@unmuhjember.ac.id
}

\begin{abstract}
Intisari - Instansi atau perusahaan merupakan tempat para pekerja atau karyawan untuk mencari sumber penghasilan. Universitas Muhammadiyah Jember merupakan instansi akademis yang setiap tahunnya memberikan penghargaan kepada semua pegawainya, yang biasanya akan diumumkan ketika acara milad. Penelitian ini bertujuan untuk membantu pihak Universitas Muhammadiyah Jember dalam memilih karyawan berprestasi. Metode yang digunakan dalam penelitian ini adalah metode profile matching. Metode profile matching digunakan untuk membandingkan selisih nilai antara profil posisi yang disebut dengan gap. Metode profile matching menggunakan beberapa tahapan dan perumusan dalam perhitungan yang meliputi pemetaan gap, pembobotan, perhitungan dan pengelompokan core dan secondary factor, perhitungan nilai total, dan perhitungan penentuan ranking. Jumlah kandidat karyawan berprestasi yang tersaring hanya 10 orang dari total keseluruhan jumlah karyawan Universitas Muhammadiyah Jember. Berdasarkan perhitungan sistem, karyawan berprestasi yang terpilih adalah Budiharto, S.H dengan nilai ranking adalah 4,79.
\end{abstract}

Kata Kunci - Sistem Pendukung Keputusan, Profile Matching, Karyawan Berprestasi

\begin{abstract}
An agency or company where workers or employees to look for a source of income. University of Muhammadiyah Jember is an academic institution which annually gives awards to all employees, which typically will be announced when the event "milad". This study aims to help the University of Muhammadiyah Jember in selecting high performing employees. The method used in this research is the method of profile matching. Method Profile matching used to compare the difference in value between profile position called the gap. Methods profile matching using multiple stages and the formulation in the calculation that includes mapping gap, weighting, calculation and grouping cores and secondary factor, the calculation of the total value, and the calculation of the ranking. Number of outstanding employee candidates as many as 10 people. Based on the calculation system, the selected high performing employees is Budiharto.
\end{abstract}

Keywords - Decision Support System, Profile Matching, Employee Achievement

\section{Pendahuluan}

Pemilihan pekerja atau karyawan berprestasi di suatu instansi atau perusahaan memiliki prosedur tersendiri agar penghargaan yang diberikan dapat meningkatkan kinerja karyawan. Universitas Muhammadiyah Jember memiliki prosedur tersendiri dalam memilih karyawan berprestasi. Prosedur pemilihan karyawan berprestasi tidak dinilai secara subjektif saja, melainkan ada beberapa pihak yang ikut dilibatkan. Pimpinan unit, dosen, dan mahasiswa ikut terlibat dalam memilih karyawan berprestasi melalui kuesioner yang diberikan oleh LPM (Lembaga Penjaminan Mutu). LPM merupakan lembaga yang ditugaskan untuk memproses kuesioner pengisian karyawan berprestasi tersebut. Faktorfaktor dalam kuesioner karyawan berprestasi meliputi komitmen keislaman dan kemuhammadiyahan, profesionalitas, dan kinerja. Prosedur pengisian kuesioner masih dilakukan secara manual, yaitu dengan mengisi kertas kuesioner kemudian dikumpulkan kembali ke LPM [1]. Hal ini tentunya menyebabkan ketidakefisiensian waktu dalam hal pengumpulan kuesioner dan penilaian kuesioner yang jumlahnya banyak karena melibatkan seluruh karyawan. Berdasarkan hal tersebut, penelitian ini mengkaji bagaimana membuat mekanisme pendukung keputusan dengan metode profile matching (pencocokan profil). Profile matching merupakan suatu mekanisme pendukung keputusan dengan mengasumsikan bahwa terdapat tingkat variabel prediktor yang ideal yang harus dipenuhi oleh subyek yang diteliti. Penggunaan metode ini untuk mencari perbandingan antara kompetensi individu ke dalam kompetensi jabatan sehingga dapat diketahui perbedaan kompetensinya (disebut juga Gap). Semakin kecil gap yang dihasilkan maka bobot nilainya semakin besar. Nilai yang semakin besar ini akan mengindikasikan karyawan tersebut memiliki banyak peluang untuk menjadi karyawan berprestasi.

\section{TINJAUAN PUSTAKA}

Penelitian sebelumnya terkait penggunaan metode profile matching sudah pernah digunakan oleh Rani Irma Handayani dengan judul Sistem Pendukung Keputusan Pemilihan Karyawan Berprestasi dengan Metode Profile Matching Pada PT. Sarana Inti Persada [2]. Aspek yang digunakan dalam pemilihan karyawan berprestasi adalah disiplin, kerjasama, dan prestasi kerja. Arief Soma Darmawan pernah menggunakan metode profile matching untuk pemilihan beasiswa bagi mahasiswa STMIK Widya Pratama [3]. Aspek yang digunakan untuk memilih mahasiswa yang akan memperoleh beasiswa adalah IPK, Penghasilan orang tua, Tanggungan orang tua, dan Semester. Abraham Obeth Petrus Sahureka pernah membahas Metode Profile Matching untuk menentukan penempatan jabatan perwira TNI AL [4]. Aspek yang digunakan untuk menentukan penempatan jabatan perwira TNI AL adalah pendidikan, riwayat kedinasan, kepribadian, kesehatan, kesegaran jasmani, psikologi, kemampuan senjata, komunikasi, dan elektronika, dan prestasi kerja. Sistem pendukung keputusan merupakan sistem berbasis komputer yang dapat membantu pengambil keputusan dengan memanfaatkan data dan model, untuk menyelesaikan masalah-masalah yang tidak terstruktur [5]. Profile matching adalah sebuah mekanisme pengambilan 
keputusan dengan mengasumsikan bahwa terdapat suatu tingkat variabel prediktor yang ideal yang harus dimiliki [6].

\section{Metodologi Penelitian}

Tahapan penyusunan penelitian ini, adalah sebagai berikut:

\section{A. Studi Literatur}

Studi literatur merupakan langkah yang dipakai untuk mencari sumber pustaka yang berhubungan dengan topik penelitian, dalam hal ini, referensi berasal dari jurnal nasional, jurnal internasional dan buku.

\section{B. Pengumpulan Data}

Pengumpulan data dilakukan dengan cara wawancara terhadap pihak LPM sebagai lembaga yang melakukan penilaian karyawan berprestasi. Data yang diperoleh selain dari hasil wawancara yaitu data kuesioner dalam bentuk cetakan maupun berkas.

\section{Perancangan Sistem}

Perancangan sistem merupakan tahapan tentang gambaran keseluruhan dari sistem yang akan dibangun.

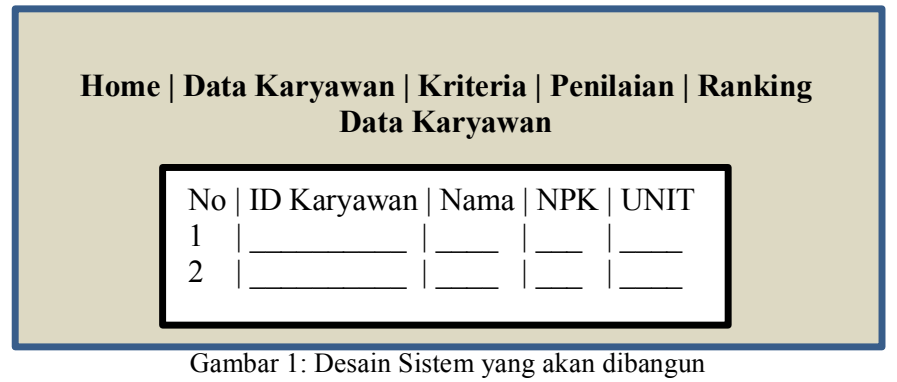

Gambar tersebut merupakan gambar desain dari sistem yang dibangun. Untuk desain pengguna sistem dalam notasi DFD (Data Flow Diagram) tidak dibuat karena pengguna sistem hanya satu pengguna (satu hak akses saja).

\section{Perhitungan manual}

Proses perhitungan manual metode profile matching digambarkan pada diagram berikut ini:

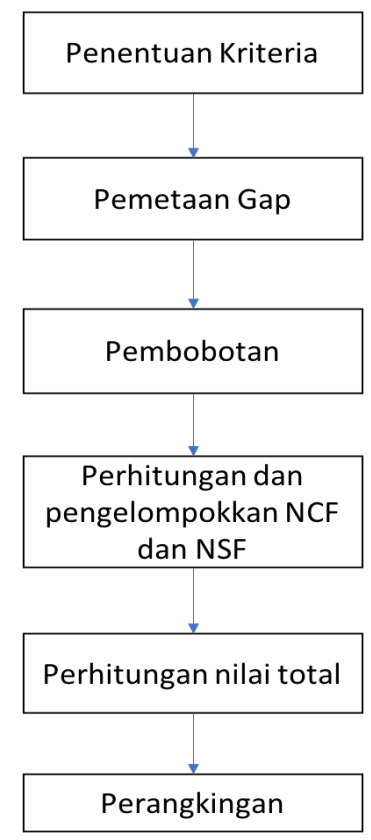

Gambar 2: Proses perhitungan manual profile matching
Penjelasan proses perhitungan pada gambar 2 tersebut, dijelaskan secara rinci sebagai berikut:

1) Penentuan kriteria

Kriteria dan bobot yang digunakan untuk menentukan karyawan berprestasi adalah

Tabel 1: Kriteria penilaian karyawan berprestasi

\begin{tabular}{|c|c|c|c|}
\hline Kriteria karyawan & $\begin{array}{c}\text { Kode } \\
\text { sub } \\
\text { kriteria }\end{array}$ & Sub kriteria & Faktor \\
\hline \multirow[t]{2}{*}{$\begin{array}{ll}\text { A. } & \text { Komitmen } \\
\text { keislaman dan } \\
\text { kemuhammadiyahan }\end{array}$} & A1 & $\begin{array}{l}\text { Aktif } \\
\text { menjalankan } \\
\text { syariat islam } \\
\text { secara baik dan } \\
\text { benar (sesuai } \\
\text { alquran dan } \\
\text { hadist) } \\
\end{array}$ & $\begin{array}{l}\text { Faktor utama } \\
\text { (core factor) }\end{array}$ \\
\hline & A2 & $\begin{array}{l}\text { Aktif dalam } \\
\text { berbagai macam } \\
\text { aktifitas } \\
\text { kegiatan } \\
\text { persyarikatan } \\
\text { muhammadiyah } \\
\text { dan ortomnya }\end{array}$ & $\begin{array}{l}\text { Faktor pendukung } \\
\text { (secondary factor) }\end{array}$ \\
\hline \multirow[t]{8}{*}{ B. Profesionalitas } & B1 & $\begin{array}{l}\text { Memiliki } \\
\text { pengetahuan } \\
\text { mengenai tugas } \\
\text { / kewajiban } \\
\text { serta mampu } \\
\text { bekerja sesuai } \\
\text { dengan tugas } \\
\text { dan tanggung } \\
\text { jawab yang } \\
\text { diberikan oleh } \\
\text { atasan }\end{array}$ & \multirow{8}{*}{$\begin{array}{l}\text { Faktor utama } \\
\text { (core factor) }\end{array}$} \\
\hline & B2 & $\begin{array}{l}\text { Memiliki } \\
\text { ketrampilan } \\
\text { untuk } \\
\text { mendukung } \\
\text { pekerjaan } \\
\text { (komputer, } \\
\text { aplikasi, office, } \\
\text { dll) }\end{array}$ & \\
\hline & B3 & $\begin{array}{l}\text { Memiliki } \\
\text { konsentrasi } \\
\text { pada tugas }\end{array}$ & \\
\hline & B4 & $\begin{array}{l}\text { Memiliki } \\
\text { kemampuan } \\
\text { teknis dalam } \\
\text { merespon atau } \\
\text { beradaptasi } \\
\text { terhadap } \\
\text { penggunaan } \\
\text { layanan sistem } \\
\text { informasi } \\
\text { akademik (sia), } \\
\text { simaku dan } \\
\text { forlap }\end{array}$ & \\
\hline & B5 & $\begin{array}{l}\text { Memiliki minat } \\
\text { untuk } \\
\text { meningkatkan } \\
\text { kemampuan } \\
\text { dalam mutu } \\
\text { layanan } \\
\text { administrasi }\end{array}$ & \\
\hline & B6 & $\begin{array}{l}\text { Jujur dalam } \\
\text { melaksanakan } \\
\text { pekerjaan }\end{array}$ & \\
\hline & B7 & $\begin{array}{l}\text { Mampu bekerja } \\
\text { sama dalam } \\
\text { meningkatkan } \\
\text { efektifitas dan } \\
\text { efisiensi kerja }\end{array}$ & \\
\hline & B8 & Kedisiplinan & \\
\hline
\end{tabular}




\begin{tabular}{|c|c|c|c|}
\hline & & $\begin{array}{l}\text { dalam } \\
\text { menjalankan } \\
\text { pekerjaan } \\
\end{array}$ & \\
\hline & B9 & $\begin{array}{l}\text { Memiliki } \\
\text { kemampuan } \\
\text { mengarahkan } \\
\text { dan } \\
\text { membimbing } \\
\text { karyawan lain } \\
\text { untuk mencapai } \\
\text { efisiensi dan } \\
\text { efektifitas } \\
\text { dalam bekerja }\end{array}$ & \multirow{3}{*}{$\begin{array}{l}\text { Faktor pendukung } \\
\text { (secondary factor) }\end{array}$} \\
\hline & B10 & $\begin{array}{l}\text { Memiliki } \\
\text { inisiatif dalam } \\
\text { melaksanakan } \\
\text { tugas dan } \\
\text { pekerjaan yang } \\
\text { relatif baru } \\
\text { baginya }\end{array}$ & \\
\hline & B11 & $\begin{array}{l}\text { Memiliki } \\
\text { kemampuan } \\
\text { berkreasi dan } \\
\text { berinovasi } \\
\text { untuk mencapai } \\
\text { hasil kerja yang } \\
\text { lebih baik }\end{array}$ & \\
\hline \multirow[t]{3}{*}{ C. Kinerja } & $\mathrm{C} 1$ & $\begin{array}{l}\text { Kualitas } \\
\text { pekerjaan yang } \\
\text { dihasilkan }\end{array}$ & \multirow{2}{*}{$\begin{array}{l}\text { Faktor Utama } \\
\text { (Core Factor) }\end{array}$} \\
\hline & $\mathrm{C} 2$ & $\begin{array}{l}\text { Ketepatan } \\
\text { waktu } \\
\text { penyelesaian } \\
\text { pekerjaan }\end{array}$ & \\
\hline & $\mathrm{C} 3$ & $\begin{array}{l}\text { Kemampuan } \\
\text { mengemban } \\
\text { pekerjaan/tugas } \\
\text { tambahan (jika } \\
\text { ada pekerjaan } \\
\text { yang diluar } \\
\text { tanggung jawab } \\
\text { utamanya) }\end{array}$ & $\begin{array}{c}\text { Faktor Pendukung } \\
\text { (Secondary } \\
\text { Factor })\end{array}$ \\
\hline
\end{tabular}

\begin{tabular}{|c|c|c|c|}
\hline \multicolumn{2}{|c|}{ Profil standar } & 5 & 5 \\
\hline 1 & 15012 & -1 & -2 \\
\hline 2 & 15013 & -1 & 0 \\
\hline 3 & 15014 & -1 & 2 \\
\hline
\end{tabular}

Warna kuning pada tabel diatas, adalah gap untuk kriteria komitmen keislaman dan kemuhammadiyahan.

\section{- Pemetaan gap kriteria profesionalitas}

Tabel 3: Pemetaan gap kriteria profesionalitas

\begin{tabular}{|c|c|c|c|c|c|c|c|c|c|c|c|c|}
\hline No & $\begin{array}{c}\text { ID } \\
\text { karyawan }\end{array}$ & \multicolumn{10}{|c|}{ Kriteria } \\
\hline & & B1 & B2 & B3 & B4 & B5 & B6 & B7 & B8 & B9 & B10 & B11 \\
\hline 1 & 15012 & B & B & SB & B & B & B & SB & B & B & B & B \\
\hline 2 & 15013 & B & SB & B & B & B & SB & B & B & B & SB & B \\
\hline 3 & 15014 & B & B & B & B & B & B & B & B & SB & B & B \\
\hline \multicolumn{10}{|c|}{ Nilai bobot karyawan } \\
\hline 1 & 15012 & 4 & 4 & 5 & 4 & 4 & 4 & 5 & 4 & 4 & 4 & 4 \\
\hline 2 & 15013 & 4 & 5 & 4 & 4 & 4 & 5 & 4 & 4 & 4 & 5 & 4 \\
\hline 3 & 15014 & 4 & 4 & 4 & 4 & 4 & 4 & 4 & 4 & 5 & 4 & 4 \\
\hline Profil standar & 5 & 5 & 5 & 5 & 5 & 5 & 5 & 5 & 5 & 5 & 5 \\
\hline 1 & 15012 & -1 & -1 & 0 & -1 & -1 & -1 & 0 & -1 & -1 & -1 & -1 \\
\hline 2 & 15013 & -1 & 0 & -1 & -1 & -1 & 0 & -1 & -1 & -1 & 0 & -1 \\
\hline 3 & 15014 & -1 & -1 & -1 & -1 & -1 & -1 & -1 & -1 & 0 & -1 & -1 \\
\hline
\end{tabular}

Warna kuning pada tabel diatas, adalah gap untuk kriteria profesionalitas.

- Pemetaan gap kriteria kinerja

Tabel 4: Pemetaan gap kriteria kinerja

\begin{tabular}{|c|c|c|c|c|c|}
\hline \multirow{2}{*}{ No } & \multirow{2}{*}{ ID karyawan } & \multicolumn{3}{|c|}{ Kriteria } & \\
\hline & & $\mathrm{C} 1$ & $\mathrm{C} 2$ & $\mathrm{C} 3$ & \\
\hline 1 & 15012 & $\mathrm{~B}$ & $\mathrm{~B}$ & $\mathrm{~B}$ & \\
\hline 2 & 15013 & SB & B & $\mathrm{B}$ & \\
\hline 3 & 15014 & $\mathrm{~B}$ & $\mathrm{C}$ & SB & \\
\hline \multicolumn{5}{|c|}{ Nilai bobot karyawan } & \\
\hline 1 & 15012 & 4 & 4 & 4 & \\
\hline 2 & 15013 & 5 & 4 & 4 & \\
\hline 3 & 15014 & 4 & 3 & 5 & \\
\hline \multicolumn{2}{|c|}{ Profil standar } & 5 & 5 & 5 & \\
\hline 1 & 15012 & -1 & -1 & -1 & \multirow{3}{*}{ gap } \\
\hline 2 & 15013 & 0 & -1 & -1 & \\
\hline 3 & 15014 & -1 & -2 & 0 & \\
\hline
\end{tabular}

\section{3) Pembobotan}

Berdasarkan gap yang sudah ditemukan pada tiap kriteria kinerja, masing-masing aspek akan diberikan bobot seperti pada tabel berikut:

Tabel 5: Bobot nilai gap

2) Pemetaan gap

Berikut ini merupakan pemetaan gap pada masing-masing kriteria:

- Pemetaan gap kriteria komitmen keislaman dan kemuhammadiyahan

Tabel 2: Pemetaan gap kriteria komitmen keislaman dan kemuhammadiyahan

\begin{tabular}{|c|c|c|c|}
\hline \multirow{2}{*}{ No } & \multirow{2}{*}{ ID karyawan } & \multicolumn{2}{|c|}{ Kriteria } \\
\cline { 3 - 4 } & & $\mathrm{A} 1$ & $\mathrm{~A} 2$ \\
\hline 1 & 15012 & $\mathrm{~B}$ & $\mathrm{~B}$ \\
\hline 2 & 15013 & $\mathrm{~B}$ & $\mathrm{SB}$ \\
\hline 3 & 15014 & $\mathrm{~B}$ & $\mathrm{C}$ \\
\hline \multicolumn{4}{|c|}{ Nilai bobot karyawan } \\
\hline 1 & 15012 & 4 & 4 \\
\hline 2 & 15013 & 4 & 5 \\
\hline 3 & 15014 & 4 & 3 \\
\hline
\end{tabular}

\begin{tabular}{|c|c|l|}
\multicolumn{2}{|c|}{ Tabel 5: Bobot nilai gap } \\
\hline Selisih & $\begin{array}{c}\text { Bobot } \\
\text { nilai }\end{array}$ & \multicolumn{1}{c|}{ Keterangan } \\
\hline 0 & 5 & $\begin{array}{l}\text { Tidak ada selisih (kompetensi sesuai dengan yang } \\
\text { dibutuhkan) }\end{array}$ \\
\hline 1 & 4,5 & Kompetensi individu kelebihan 1 tingkat / level \\
\hline-1 & 4 & Kompetensi individu kekurangan 1 tingkat / level \\
\hline 2 & 3,5 & Kompetensi individu kelebihan 2 tingkat / level \\
\hline-2 & 3 & Kompetensi individu kekurangan 2 tingkat / level \\
\hline 3 & 2,5 & Kompetensi individu kelebihan 3 tingkat / level \\
\hline-3 & 2 & Kompetensi individu kekurangan 3 tingkat / level \\
\hline 4 & 1,5 & Kompetensi individu kelebihan 4 tingkat / level \\
\hline-4 & 1 & Kompetensi individu kekurangan 4 tingkat / level \\
\hline
\end{tabular}


Tabel 6: Hasil bobot nilai gap kriteria komitmen keislaman dan kemuhammadiyahan

\begin{tabular}{|c|c|c|c|}
\hline \multirow{2}{*}{ No } & \multirow{2}{*}{ ID karyawan } & \multicolumn{2}{|c|}{ Kriteria } \\
\cline { 3 - 4 } & & $\mathrm{A} 1$ & $\mathrm{~A} 2$ \\
\hline 1 & 15012 & 4 & 4 \\
\hline 2 & 15013 & 4 & 5 \\
\hline 3 & 15014 & 4 & 3 \\
\hline
\end{tabular}

Tabel 7: Hasil bobot nilai gap kriteria profesionalitas

\begin{tabular}{|c|c|c|c|c|c|c|c|c|c|c|c|c|}
\hline \multirow{2}{*}{ No } & \multirow{2}{*}{$\begin{array}{c}\text { ID } \\
\text { karyawan }\end{array}$} & \multicolumn{11}{|c|}{ Kriteria } \\
\hline & & B1 & B2 & B3 & B4 & B5 & B6 & B7 & B8 & B9 & B10 & B11 \\
\hline 1 & 15012 & 4 & 4 & 5 & 4 & 4 & 4 & 5 & 4 & 4 & 4 & 4 \\
\hline 2 & 15013 & 4 & 5 & 4 & 4 & 4 & 5 & 4 & 4 & 4 & 5 & 4 \\
\hline 3 & 15014 & 4 & 4 & 4 & 4 & 4 & 4 & 4 & 4 & 5 & 4 & 4 \\
\hline
\end{tabular}

Tabel 8: Hasil bobot nilai gap kriteria kinerja
\begin{tabular}{|c|c|c|c|c|}
\hline \multirow{2}{*}{ No } & \multirow{2}{*}{ ID Karyawan } & \multicolumn{3}{|c|}{ Kriteria } \\
\cline { 3 - 5 } & & $\mathrm{C} 1$ & $\mathrm{C} 2$ & $\mathrm{C} 3$ \\
\hline 1 & 15012 & 4 & 4 & 4 \\
\hline 2 & 15013 & 5 & 4 & 4 \\
\hline 3 & 15014 & 4 & 3 & 5 \\
\hline
\end{tabular}

4) Perhitungan dan pengelompokkan NCF dan NSF

Setelah nilai bobot gap diketahui, kemudian lakukan perhitungan dan pengelompokkan core factor dan secondary factor, perhitungannya adalah sebagai berikut:

- Kriteria komitmen keislaman dan kemuhammadiyahan

$$
\mathrm{NCF}_{\mathrm{A}}=\frac{A 1}{1} \quad \mathrm{NSF}_{\mathrm{A}}=\frac{A 2}{1}
$$

1. $\mathrm{NCF}_{\mathrm{A}}=\frac{4}{1}=4$

$$
\begin{aligned}
& \mathrm{NSF}_{\mathrm{A}}=\frac{4}{1}=4 \\
& \mathrm{NSF}_{\mathrm{A}}=\frac{5}{1}=5 \\
& \mathrm{NSF}_{\mathrm{A}}=\frac{3}{1}=3
\end{aligned}
$$

3. $\mathrm{NCF}_{\mathrm{A}}=\frac{4}{1}=4$

Tabel 9: Pengelompokkan bobot nilai gap kriteria komitmen keislaman dan kemuhammadiyahan

\begin{tabular}{|c|c|c|c|c|c|}
\hline \multirow{2}{*}{ No } & \multirow{2}{*}{ ID karyawan } & \multicolumn{2}{|c|}{ Kriteria } & \multirow{2}{*}{ Core } & \multirow{2}{*}{ Secondary } \\
\cline { 3 - 4 } & & $\mathrm{A} 1$ & $\mathrm{~A} 2$ & & 4 \\
\hline 1 & 15012 & 4 & 4 & 4 & 5 \\
\hline 2 & 15013 & 4 & 5 & 4 & 3 \\
\hline 3 & 15014 & 4 & 3 & 4 & 4 \\
\hline
\end{tabular}

\begin{tabular}{|c|c|c|c|c|c|c|c|c|c|c|c|c|c|c|}
\hline \multirow[b]{2}{*}{$\begin{array}{l}\mathrm{N} \\
\mathrm{o}\end{array}$} & \multirow[b]{2}{*}{$\begin{array}{l}\text { ID } \\
\text { karya } \\
\text { wan }\end{array}$} & \multicolumn{11}{|c|}{ Kriteria } & \multirow{2}{*}{$\begin{array}{c}\text { Cor } \\
\mathrm{e}\end{array}$} & \multirow{2}{*}{$\begin{array}{c}\text { Secon } \\
\text { dary }\end{array}$} \\
\hline & & $\begin{array}{l}\text { B } \\
1\end{array}$ & $\begin{array}{l}\text { B } \\
2\end{array}$ & $\begin{array}{l}\text { B } \\
3\end{array}$ & $\begin{array}{l}\text { B } \\
4\end{array}$ & $\begin{array}{l}\text { B } \\
5\end{array}$ & $\begin{array}{l}\text { B } \\
6\end{array}$ & $\begin{array}{l}\text { B } \\
7\end{array}$ & $\begin{array}{l}\text { B } \\
8\end{array}$ & $\begin{array}{l}\text { B } \\
9\end{array}$ & $\begin{array}{l}\mathrm{B} \\
1 \\
0\end{array}$ & $\begin{array}{l}\mathrm{B} \\
1 \\
1\end{array}$ & & \\
\hline 1 & 15012 & 4 & 4 & 5 & 4 & 4 & 4 & 5 & 4 & 4 & 4 & 4 & 4,25 & 4 \\
\hline $\begin{array}{l}\mathrm{N} \\
\mathrm{o}\end{array}$ & $\begin{array}{c}\text { ID } \\
\text { karya } \\
\text { wan }\end{array}$ & $\begin{array}{l}\text { B } \\
1\end{array}$ & $\begin{array}{l}\text { B } \\
2\end{array}$ & $\begin{array}{l}\text { B } \\
3\end{array}$ & $\begin{array}{l}\text { B } \\
4\end{array}$ & $\begin{array}{l}\text { B } \\
5\end{array}$ & $\begin{array}{l}\text { B } \\
6\end{array}$ & $\begin{array}{l}\text { B } \\
7\end{array}$ & $\begin{array}{l}\text { B } \\
8\end{array}$ & $\begin{array}{l}\text { B } \\
9\end{array}$ & $\begin{array}{l}\mathrm{B} \\
1 \\
0\end{array}$ & $\begin{array}{l}\mathrm{B} \\
1 \\
1\end{array}$ & $\begin{array}{c}\text { Cor } \\
\text { e }\end{array}$ & $\begin{array}{l}\text { Secon } \\
\text { dary }\end{array}$ \\
\hline 2 & 15013 & 4 & 5 & 4 & 4 & 4 & 5 & 4 & 4 & 4 & 5 & 4 & 4,25 & 4,34 \\
\hline 3 & 15014 & 4 & 4 & 4 & 4 & 4 & 4 & 4 & 4 & 5 & 4 & 4 & 4 & 4,34 \\
\hline
\end{tabular}

- Kriteria profesionalitas

$$
\begin{array}{lll}
\mathrm{NCF}_{\mathrm{B}}=\frac{B 1+B 2+B 3+B 4+B 5+B 6+B 7+B 8}{8} & \mathrm{NSF}_{\mathrm{B}}=\frac{B 9+B 10+B 11}{3} \\
\text { 1. } \mathrm{NCF}_{\mathrm{B}}=\frac{4+4+5+4+4+4+5+4}{8}=4,25 & \mathrm{NSF}_{\mathrm{B}}=\frac{4+4+4}{3}=4 \\
\text { 2. } \mathrm{NCF}_{\mathrm{B}}=\frac{4+5+4+4+4+5+4+4}{8}=4,25 & \mathrm{NSF}_{\mathrm{B}}=\frac{4+5+4}{3}=4,34 \\
\text { 3. } \mathrm{NCF}_{\mathrm{B}}=\frac{4+4+4+4+4+4+4+4}{8}=4 & \mathrm{NSF}_{\mathrm{B}}=\frac{5+4+4}{3}=4,34
\end{array}
$$

Tabel 10: Pengelompokkan bobot nilai gap kriteria profesional

- Kriteria kinerja

$$
\mathrm{NCF}_{\mathrm{C}}=\frac{C 1+C 2}{2} \quad \mathrm{NSF}_{\mathrm{C}}=\frac{C 3}{1}
$$

\begin{tabular}{|c|c|c|c|c|c|c|}
\hline \multirow{2}{*}{ No } & \multirow{2}{*}{ ID karyawan } & \multicolumn{3}{|c|}{ Kriteria } & \multirow{2}{*}{ Core } & \multirow{2}{*}{ Secondary } \\
\hline & & $\mathrm{C} 1$ & $\mathrm{C} 2$ & $\mathrm{C} 3$ & & \\
\hline 1 & 15012 & 4 & 4 & 4 & 4 & 4 \\
\hline 2 & 15013 & 5 & 4 & 4 & 4,5 & 4 \\
\hline 3 & 15014 & 4 & 3 & 5 & 3,5 & 5 \\
\hline
\end{tabular}
1. $\mathrm{NCF}_{\mathrm{C}}=\frac{4+4}{2}=4$
$\mathrm{NSF}_{\mathrm{C}}=\frac{4}{1}=4$
2. $\mathrm{NCF}_{\mathrm{C}}=\frac{5+4}{2}=4$
$\mathrm{NSF}_{\mathrm{C}}=\frac{4}{1}=4$
3. $\mathrm{NCF}_{\mathrm{C}}=\frac{4+3}{2}=4$
$\mathrm{NSF}_{\mathrm{C}}=\frac{5}{1}=5$

Tabel 11: Pengelompokkan bobot nilai gap kriteria kinerja

5) Perhitungan nilai total

Untuk menghitung nilai total, maka terlebih dahulu harus menentukan persentase core factor dan secondary factor. Pada kasus ini, core factor ditentukan sebesar $60 \%$ dan secondary factor sebesar $40 \%$. Nilai ini diperoleh ketika berdiskusi dengan pihak LPM Universitas Muhammadiyah Jember.

- Nilai total kriteria komitmen keislaman dan kemuhammadiyahan

ID $=15012$

$\mathrm{N}_{\mathrm{A}}=(\mathrm{x}) \% \mathrm{NCF}+(\mathrm{x}) \% \mathrm{NSF}$

$\mathrm{N}_{\mathrm{A}}=(60 \% \mathrm{x} 4)+(40 \% \mathrm{x} 4)$

$\mathrm{N}_{\mathrm{A}}=2,4+1,6=4$

ID $=15013$

$\mathrm{N}_{\mathrm{A}}=(\mathrm{x}) \% \mathrm{NCF}+(\mathrm{x}) \% \mathrm{NSF}$

$\mathrm{N}_{\mathrm{A}}=(60 \% \mathrm{x} 4)+(40 \% \times 5)$

$\mathrm{N}_{\mathrm{A}}=2,4+2=4,4$

ID $=15014$

$\mathrm{N}_{\mathrm{A}}=(\mathrm{x}) \% \mathrm{NCF}+(\mathrm{x}) \% \mathrm{NSF}$

$\mathrm{N}_{\mathrm{A}}=(60 \% \times 4)+(40 \% \times 5)$

$\mathrm{N}_{\mathrm{A}}=2,4+2=4,4$

Tabel 12: Nilai total kriteria komitmen keislaman dan kemuhammadiyahan

\begin{tabular}{|c|c|c|c|c|}
\hline No & ID karyawan & Core & Secondary & Nilai total \\
\hline 1 & 15012 & 4 & 4 & 4 \\
\hline 2 & 15013 & 4 & 5 & 4,4 \\
\hline 3 & 15014 & 4 & 3 & 3,6 \\
\hline
\end{tabular}

- Nilai total profesionalitas

ID $=15012$

$\mathrm{N}_{\mathrm{A}}=(\mathrm{x}) \% \mathrm{NCF}+(\mathrm{x}) \% \mathrm{NSF}$

$\mathrm{N}_{\mathrm{A}}=(60 \% \times 4,25)+(40 \% \times 4)$

$\mathrm{N}_{\mathrm{A}}=2,55+1,6=4,15$

ID $=15013$

$\mathrm{N}_{\mathrm{A}}=(\mathrm{x}) \% \mathrm{NCF}+(\mathrm{x}) \% \mathrm{NSF}$

$\mathrm{N}_{\mathrm{A}}=(60 \% \mathrm{x} 4,25)+(40 \% \mathrm{x} 4,34)$

$\mathrm{N}_{\mathrm{A}}=2,55+1,736=4,286$

ID $=15014$

$\mathrm{N}_{\mathrm{A}}=(\mathrm{x}) \% \mathrm{NCF}+(\mathrm{x}) \% \mathrm{NSF}$

$\mathrm{N}_{\mathrm{A}}=(60 \% \mathrm{x} 4)+(40 \% \mathrm{x} 4,34)$

$\mathrm{N}_{\mathrm{A}}=2,4+1,736=4,136$

Tabel 13: Nilai total kriteria profesionalitas

\begin{tabular}{|c|c|c|c|c|}
\hline No & ID karyawan & Core & Secondary & Nilai total \\
\hline 1 & 15012 & 4,25 & 4 & 4,15 \\
\hline 2 & 15013 & 4,25 & 4,34 & 4,286 \\
\hline 3 & 15014 & 4 & 4,34 & 4,136 \\
\hline
\end{tabular}


- Nilai total kinerja

ID $=15012$

$\mathrm{N}_{\mathrm{A}}=(\mathrm{x}) \% \mathrm{NCF}+(\mathrm{x}) \% \mathrm{NSF}$

$\mathrm{N}_{\mathrm{A}}=(60 \% \mathrm{x} 4)+(40 \% \mathrm{x} 4)$

$\mathrm{N}_{\mathrm{A}}=2,4+1,6=4$

ID $=15013$

$\mathrm{N}_{\mathrm{A}}=(\mathrm{x}) \% \mathrm{NCF}+(\mathrm{x}) \% \mathrm{NSF}$

$\mathrm{N}_{\mathrm{A}}=(60 \% \times 4,5)+(40 \% \times 4)$

$\mathrm{N}_{\mathrm{A}}=2,7+1,6=4,3$

ID $=15014$

$\mathrm{N}_{\mathrm{A}}=(\mathrm{x}) \% \mathrm{NCF}+(\mathrm{x}) \% \mathrm{NSF}$

$\mathrm{N}_{\mathrm{A}}=(60 \% \times 3,5)+(40 \% \times 5)$

$\mathrm{N}_{\mathrm{A}}=2,1+2=4,1$

Tabel 14: Nilai total kriteria kinerja

\begin{tabular}{|c|c|c|c|c|}
\hline No & ID karyawan & Core & Secondary & Nilai total \\
\hline 1 & 15012 & 4 & 4 & 4 \\
\hline 2 & 15013 & 4,5 & 4 & 4,3 \\
\hline 3 & 15014 & 3,5 & 5 & 4,1 \\
\hline
\end{tabular}

6) Pemeringkatan

Hasil akhir dari metode profile matching adalah peringkat atau ranking dari kandidat karyawan berprestasi tersebut.

$\mathrm{ID}=15012$

Ranking $=(\mathrm{x}) \% \mathrm{~N}_{\mathrm{A}}=(\mathrm{x}) \% \mathrm{~N}_{\mathrm{B}}+(\mathrm{x}) \% \mathrm{~N}_{\mathrm{C}}$

Ranking $=(35 \% \mathrm{x} 4)+(40 \% \mathrm{x} 4,15)+(25 \% \mathrm{x} 4)$

Ranking $=1,4+1,66+1=4,06$

$\mathrm{ID}=15013$

Ranking $=(\mathrm{x}) \% \mathrm{~N}_{\mathrm{A}}=(\mathrm{x}) \% \mathrm{~N}_{\mathrm{B}}+(\mathrm{x}) \% \mathrm{~N}_{\mathrm{C}}$

Ranking $=(35 \% \mathrm{x} 4,4)+(40 \% \mathrm{x} 4,286)+(25 \% \mathrm{x} 4,3)$

Ranking $=1,54+1,7144+1,075=4,3294$

$\mathrm{ID}=15014$

Ranking $=(\mathrm{x}) \% \mathrm{~N}_{\mathrm{A}}=(\mathrm{x}) \% \mathrm{~N}_{\mathrm{B}}+(\mathrm{x}) \% \mathrm{~N}_{\mathrm{C}}$

Ranking $=(35 \%$ x 3,6) $+(40 \% \times 4,136)+(25 \% \times 4,1)$

Ranking $=1,26+1,6544+1,025=3,9394$

Tabel 15: Ranking karyawan

\begin{tabular}{|c|c|c|c|c|c|c|c|c|c|}
\hline \multirow[b]{2}{*}{$\begin{array}{l}\mathrm{N} \\
\mathrm{o}\end{array}$} & \multirow{2}{*}{$\begin{array}{c}\text { ID } \\
\text { karyawa } \\
\text { n }\end{array}$} & \multicolumn{3}{|c|}{ Nilai kriteria } & \multirow{2}{*}{$\begin{array}{c}\text { Total } \\
\text { nilai } \\
\text { rankin } \\
g\end{array}$} & \multirow[b]{2}{*}{$\begin{array}{c}\text { Rangkin } \\
g\end{array}$} & \multirow[b]{2}{*}{ NPK } & \multirow[b]{2}{*}{ Nama } & \multirow[b]{2}{*}{ Unit } \\
\hline & & A & B & $\mathrm{C}$ & & & & & \\
\hline 1 & 15013 & $\begin{array}{r}4, \\
4\end{array}$ & $\begin{array}{c}4,28 \\
6 \\
\end{array}$ & $\begin{array}{r}4, \\
3 \\
\end{array}$ & 4,33 & 1 & $\begin{array}{c}810600 \\
2 \\
\end{array}$ & $\begin{array}{c}\text { M.Sofiand } \\
\mathrm{i}\end{array}$ & $\begin{array}{c}\text { BA } \\
\text { U }\end{array}$ \\
\hline 2 & 15012 & 4 & 4,15 & 4 & 4,06 & 2 & $\begin{array}{c}830106 \\
4\end{array}$ & $\begin{array}{c}\text { Kasim } \\
\text { maryono }\end{array}$ & $\begin{array}{c}\text { BA } \\
\text { U }\end{array}$ \\
\hline 3 & 15014 & $\begin{array}{l}3, \\
6\end{array}$ & $\begin{array}{c}4,13 \\
6\end{array}$ & $\begin{array}{l}4, \\
1\end{array}$ & 3,94 & 3 & $\begin{array}{c}830908 \\
0\end{array}$ & Mundir & $\begin{array}{c}\text { BA } \\
\text { U }\end{array}$ \\
\hline
\end{tabular}

Dari ketiga sampel karyawan tersebut, maka nilai total ranking yang tertinggi akan direkomendasikan sebagai karyawan berprestasi. Diharapkan dengan penggunaan sistem ini, proses manual dapat diganti dengan komputerisasi tanpa menghilangkan kualitas yang sudah berjalan sebelumnya.

\section{Implementasi Metode Pada Sistem}

Implementasi metode profile matching pada aplikasi diterapkan dalam bentuk aplikasi berbasis web.

\section{E. Pengujian Sistem}

Pengujian sistem dilakukan untuk menguji perangkat lunak agar dapat mengetahui respon dari pengguna sistem, perhitungan karyawan berprestasi berdasarkan standar dari Universitas Muhammadiyah Jember, dan kelemahan sistem dalam bentuk bug yang terdapat pada aplikasi.

\section{HASIL DAN PEMBAHASAN}

Berdasarkan proses yang sudah dijelaskan pada metodologi penelitian, berikut merupakan penerapan perhitungan metode profile matching pada sistem informasi berbasis web.

\section{A. Nilai profil ideal}

Penerapan nilai profil ideal pada sistem terdapat pada gambar berikut ini:

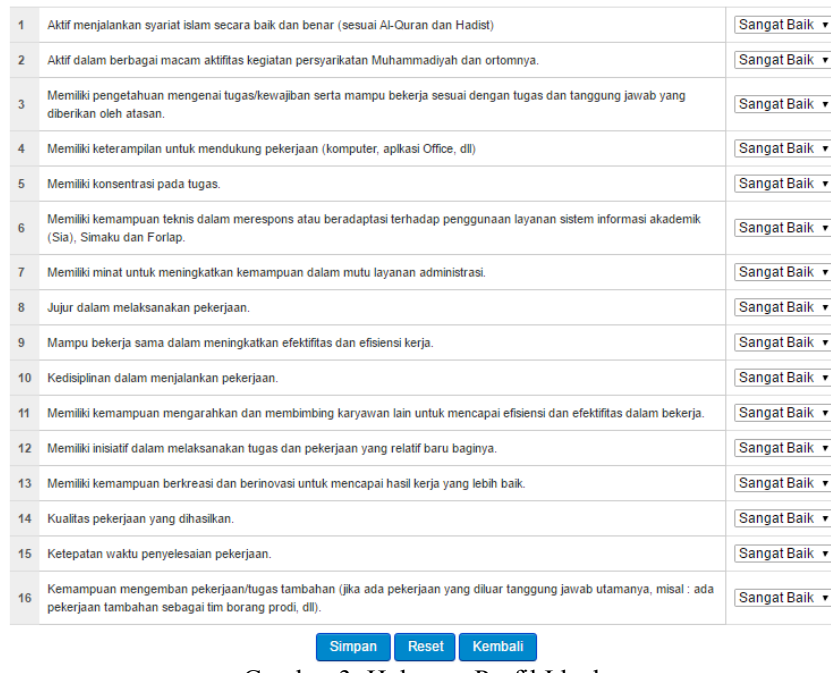

Gambar 3: Halaman Profil Ideal

\section{B. Penilaian karyawan}

Penerapan proses penilaian karyawan agar dapat terpilih sebagai kandidat karyawan berprestasi terdapat pada gambar berikut ini:

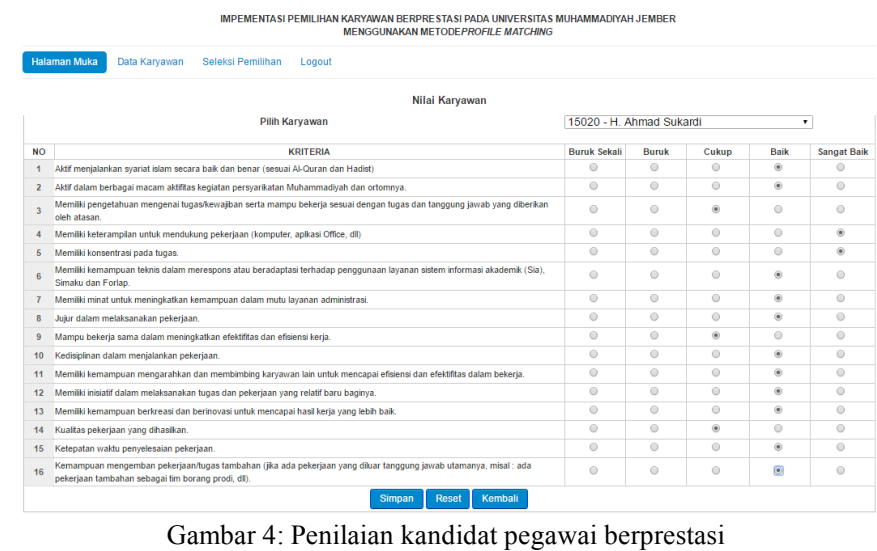

C. Perhitungan gap, nilai total dan ranking

Perhitungan gap dari semua karyawan yang diusulkan oleh pihak LPM sebagai kandidat karyawan berprestasi adalah sebagai berikut:

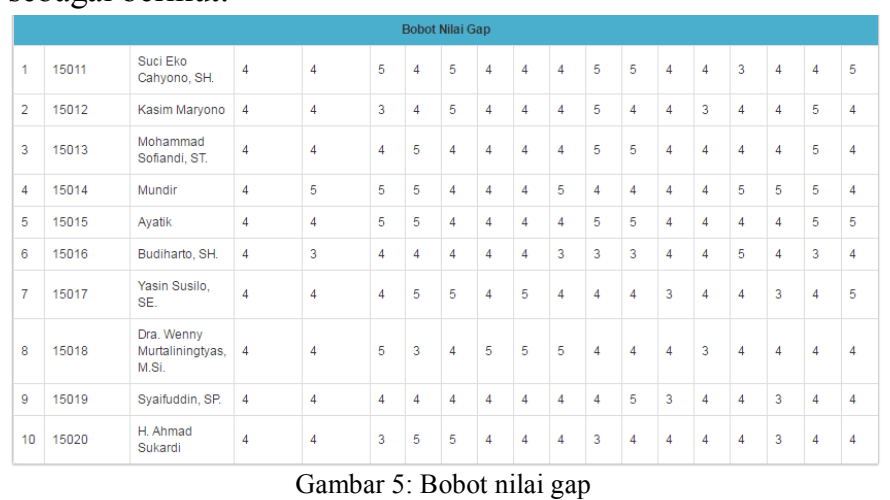


Nilai total yang diperoleh kandidat karyawan berprestasi adalah sebagai berikut:

\begin{tabular}{|l|l|l|l|l|l|}
\hline \multicolumn{5}{|c|}{ Nilai Total } \\
\hline No & IDPeserta & \multicolumn{1}{|c|}{ Nama } & $\begin{array}{l}\text { Komitmen Keislaman dan } \\
\text { Kemuhammadiyahan }\end{array}$ & Profisionalitas & Kinerja \\
\hline 1 & 15011 & Suci Eko Cahyono, SH. & 4 & 4.17 & 4.4 \\
\hline 2 & 15012 & Kasim Maryono & 4 & 3.95 & 4.3 \\
\hline 3 & 15013 & Mohammad Sofiandi, ST. & 4 & 4.23 & 4.3 \\
\hline 4 & 15014 & Mundir & 4.4 & 4.36 & 4.6 \\
\hline 5 & 15015 & Ayatik & 4 & 4.3 & 4.7 \\
\hline 6 & 15016 & Budiharto, SH. & 3.6 & 3.91 & 3.7 \\
\hline 7 & 15017 & Yasin Susilo, SE. & 4 & 4.1 & 4.1 \\
\hline 8 & 15018 & $\begin{array}{l}\text { Dra. Wenny } \\
\text { Murtaliningtyas, M.Si. }\end{array}$ & 4 & 4.1 & 4 \\
\hline 9 & 15019 & Syaifuddin, SP. & 4 & 3.95 & 3.7 \\
\hline 10 & 15020 & H. Ahmad Sukardi & 4 & 4 & 3.7 \\
\hline & & Gambar 6: Nilai & 41 kandidat karyawan ber. & \\
\hline
\end{tabular}

Gambar 6: Nilai total kandidat karyawan berprestasi

Ranking akhir dari proses metode profile matching adalah sebagai berikut:

\begin{tabular}{|c|c|c|c|}
\hline \multicolumn{4}{|c|}{ Ranking } \\
\hline No & IDPeserta & Nama & Nilai Ranking \\
\hline 1 & 15014 & Mundir & 4.43 \\
\hline 2 & 15015 & Ayatik & 4.30 \\
\hline 3 & 15011 & Suci Eko Cahyono, SH. & 4.17 \\
\hline 4 & 15013 & Mohammad Sofiandi, ST. & 4.17 \\
\hline 5 & 15012 & Kasim Maryono & 4.06 \\
\hline 6 & 15017 & Yasin Susilo, SE. & 4.06 \\
\hline 7 & 15018 & Dra. Wenny Murtaliningtyas, M.Si. & 4.04 \\
\hline 8 & 15020 & H. Ahmad Sukardi & 3.92 \\
\hline 9 & 15019 & Syaifuddin, SP. & 3.90 \\
\hline 10 & 15016 & Budiharto, SH. & 3.75 \\
\hline
\end{tabular}

Gambar 7: Ranking akhir dari karyawan berprestasi

\section{Pengujian metode profile matching}

Pengujian terhadap metode profile matching, dilakukan dengan dua tahapan, yaitu:

- Ujicoba perhitungan pertama

Ujicoba perhitungan pertama menggunakan standar profil tertinggi dengan nilai tertinggi yaitu 5 (lima) atau sangat baik.

- Ujicoba perhitungan kedua

Ujicoba perhitungan kedua menggunakan standar profil ideal dengan nilai 3 (cukup).

Gambar berikut ini menjelaskan perhitungan secara manual yang membandingkan antara profil tertinggi (5) dan profil ideal (3) sehingga didapatkan hasil akhir (ranking) sebagai berikut:

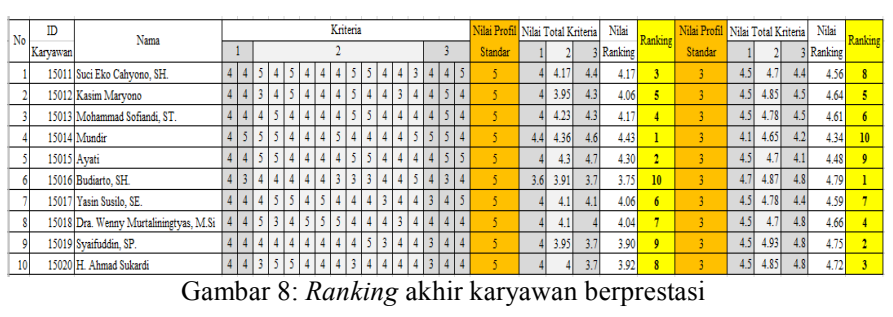

Berdasarkan hasil perhitungan kedua ujicoba yang telah dilakukan, maka karyawan yang terpilih sebagai karyawan berprestasi setelah diproses dengan metode profile matching adalah Budiharto, S.H. Namun, bukan berarti hasil ini adalah hasil yang nanti akan diterima oleh LPM atau Universitas Muhammadiyah Jember. Hasil yang diperoleh sistem hanya hasil rekomendasi sesuai dengan fakta atau data-data yang sudah diberikan kepada mahasiswa, pimpinan unit, maupun rekan-rekan sesama karyawan dan diproses sebagai data primer pada penelitian ini.

\section{KESIMPULAN}

Berdasarkan perhitungan manual dan pengujian sistem yang sudah diteliti, maka dapat disimpulkan beberapa hal sebagai berikut:

- Perhitungan pemilihan karyawan berprestasi dengan metode profile matching kurang tepat karena metode ini menggunakan perhitungan nilai standar yang nantinya dapat menghasilkan nilai akhir yang nantinya tidak sesuai dengan penilaian yang sebenarnya. Akan tetapi hal tersebut dapat diantisipasi jika peneliti tidak menggunakan nilai standar atau nilai ideal, namun dengan nilai tertinggi dari penilaian yang sebenarnya

- Berdasarkan jumlah data karyawan secara keseluruhan, maka karyawan bernama Budiharto, S.H terpilih sebagai karyawan berprestasi setelah memperoleh nilai ranking akhir 4,79

\section{REFERENSI}

[1] T. A. Cahyanto, "Implementasi Smart Router Berbasis OpenWRT Sebagai Media Untuk File Sharing dan Chatting Pada Laboratorium Terpadu Unmuh Jember," 2018.

[2] R. I. Handayani, "Sistem Pendukung Keputusan Pemilihan Karyawan Berprestasi Dengan Metode Profile Matching Pada Pt. Sarana Inti Persada (Sip)," J. Pilar Nusa Mandiri, vol. 13, no. 1, pp. 28-34, 2017.

[3] A. S. Darmawan, "Pemilihan Beasiswa Bagi Mahasiswa Stmik Widya Pratama Dengan Metode Profile Matching," no. 1, pp. 1-5, 2012.

[4] A. O. P. Sahureka, "Decision Support Systems in the Placement of Electronic Officers of Indonesian Navy with Profile Matching Method," Int. J. Eng. Res. Technol., vol. 6, no. 1, pp. 458-465, 2017.

[5] E. Turban, J. E. Aronson, and T.-P. Liang, Decision Support Systems and Intelligent Systems. Pearson/Prentice Hall, 2005.

[6] Kusrini, Konsep dan Aplikasi Sistem Pendukung Keputusan, 1st ed. Yogyakarta: Penerbit Andi, 2007. 